\title{
A combined Euler deconvolution and tilt angle method for interpretation of magnetic data in the South region
}

\author{
Hai Nguyen Hong ${ }^{1,2}$, Vuong Vo Van ${ }^{1}$, Liet Dang Van ${ }^{1, *}$
}

${ }^{1}$ University of Science, VNU-HCM

${ }^{2}$ An Giang University

Correspondence

Liet Dang Van, University of Science, VNU-HCM

Email: dangvanliet@gmail.com

\section{History}

- Received: 2018-12-04

- Accepted: 2019-04-15

- Published: 2019-06-07

DOI :

https://doi.org/10.32508/stdj.v22i2.1226

\section{Check for updates}

\section{Copyright}

(.) VNU-HCM Press. This is an openaccess article distributed under the terms of the Creative Commons Attribution 4.0 International license.

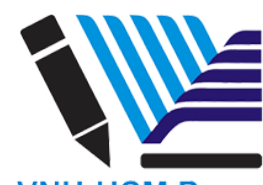

VNU-HCM Press

\begin{abstract}
Introduction: The purpose of this paper is to determinate the position, depth, dip direction and dip angle the faults in the South region of Vietnam from the total magnetic intensity anomalies, that reduced to the magnetic pole (RTP). Methods: Based on the Oasis Montaj software, we proposed a new way to compute the positions and the depth to the top of the faults by combining the Tilt angle and the Euler deconvolution methods. In addition, the angle and direction of the dip of theses faults were also determined by considering maximum of the total horizontal derivative of the RTP upward continuation at the different height levels. Results: The results show that there are 12 faults along the longitudinal direction, latitudinal direction, Northwest - Southeast direction and Northeast - Southwest direction with the mazimum depth is about $3100 \mathrm{~m}$ and the dip angle changes in the range of $65-82^{\circ}$. Conclusion: These indicate that these methods are valuable tools for specifying the characteristics of geology, contribute to give and confirm the useful information on geological structure in the South region of Vietnam.

Key words: Euler deconvolution, tilt angle, South region
\end{abstract}

\section{INTRODUCTION}

Determining the dip direction, dip angle and depth of the faults are important steps in the interpretation of magnetic/gravity data. So, there are many methods proposed to solve this problem. To determine the position of the faults, the most commonly method is that using the maximum values of the total horizontal derivatives of the RTP field or the pseudogravity field ${ }^{1}$. In while, the depth of the sources is determined by the statistical methods of Spector and Grant $(1970)^{2}$. Due to the importance of problem, many other methods have been proposed in the past to determine the position of the boundary and the depth of the source individually or the combination of both, such as the Werner method Werner method ${ }^{3,4}$, Euler deconvolution ${ }^{5,6} \ldots$ and a recent method is tilt angle $\operatorname{method}^{7,8}$.

In Southern Vietnam, there were a number of fault determination studies from the gravity data such as: Cao Dinh Trieu et.al. in $2002^{9}$, Le Huy Minh et al. in $2002^{10}$, Cao Dinh Trieu in $2005^{11}$, Dang Thanh Hai et al. in $2006^{12}$, Nguyen Hong Hai et al. in $2016^{13}$. In which, the studies only determined the position of the fault, did not determine the depth and only a few faults according to the Northwest - Southeast direction are determined the dip angle. Therefore, this paper aims to address the above shortcomings by analyzing the total magnetic intensity anomalies map, that reduced to the magnetic pole (RTP).

For determinating the position and the depth of faults, we proposed a new way by combining the Tilt angle and the Euler deconvolution methods. The tilt angle method was first proposed by Miller and Singh in $1994^{14}$; then, was further developed by Verduzco et al. in $2004^{15}$ to determinate the position of faults and the Euler deconvolution method was proposed by Thompson in $1982^{5}$ and Reid et al. in $1990^{6}$ to estimate the depth to the top of faults. The combination of the two methods based on the Oasis Montaj software $8.4^{16}$. Firstly, the tilt angle method was used to delineate the faults ( 0 contour); then, the Euler deconvolution was applied along the 0 contour of tilt to determine the depth of the faults. This one was intended to overcome the shortcomings of each method. Furthemore, the angle and direction of these faults were also determined by considering maximum of the total horizontal derivative of the RTP upward continuation at the different height levels.

\section{METHODOLOGY}

\section{Tilt angle method}

The tilt angle (Figure 1) is defined as ${ }^{14}$ :

$$
\theta=\mathrm{TDR}=\tan ^{-1}\left(\frac{\partial \mathrm{T}}{\partial \mathrm{z}} / \frac{\partial \mathrm{T}}{\partial \mathrm{h}}\right)
$$


Where, $\frac{\partial T}{\partial h}=\sqrt{\left(\frac{\partial T}{\partial x}\right)^{2}}$ in 2-D and $\frac{\partial \mathrm{T}}{\partial \mathrm{h}}=$ $\sqrt{\left(\frac{\partial T}{\partial x}\right)^{2}+\left(\frac{\partial T}{\partial y}\right)^{2}}$ in $3-D, \frac{\partial T}{\partial x}, \frac{\partial T}{\partial y}, \frac{\partial T}{\partial z}$ are first order derivatives of magnetic field $\mathrm{T}$ in the $\mathrm{x}-, \mathrm{y}$ and $\mathrm{z}$ - directions.

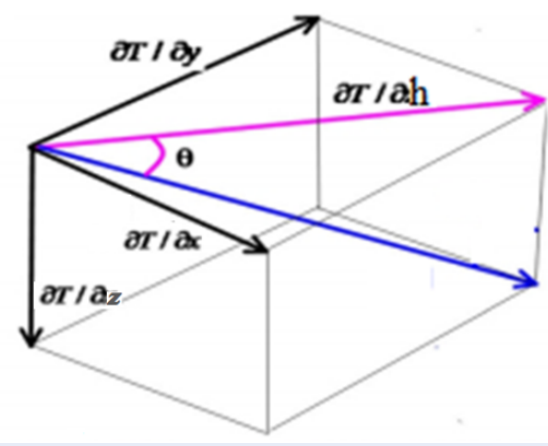

Figure 1: Tilt angle.

The tilt angle is the ratio of the vertical and horizontal derivatives. Because the horizontal derivative enhances the boundaries (faults) and the vertical derivative narrows the width of the anomaly, so the zero contours $\left(\theta=0^{\circ}\right)$ delineate the spatial location of the boundary sources, whilst the depth to the sources are directly identified the contours drawn on the map that is the distance between the zero and either the $-45^{\circ}$ or the $+45^{\circ}$ contours (handwork depth estimation). In this paper, we only use this method to determine the position of the faults.

\section{Standard 3D-Euler Deconvolution method}

Recently, using of the Euler deconvolution has become more widespread because it has been automated and rapid interpretation that work with either profile or grid data ${ }^{17-20}$. This method is based on the homogeneous equation. The 3D form of Euler's equation can be defined ${ }^{6}$ :

$$
\begin{aligned}
& \left(\mathrm{x}-\mathrm{x}_{0}\right) \frac{\partial \Delta \mathrm{T}}{\partial \mathrm{x}}+\left(\mathrm{y}-\mathrm{y}_{0}\right) \frac{\partial \Delta \mathrm{T}}{\partial \mathrm{y}}+ \\
& \left(\mathrm{z}-\mathrm{z}_{0}\right) \frac{\partial \Delta \mathrm{T}}{\partial \mathrm{z}}=\mathrm{N}\left(\Delta \mathrm{T}_{\mathrm{kv}}-\Delta \mathrm{T}\right)
\end{aligned}
$$

where, $\mathrm{x}_{0}, \mathrm{y}_{0}, \mathrm{z}_{0}$ are the coordinates of the magnetic source whose anomaly $\Delta \mathrm{T}$ is detected at $(\mathrm{x}, \mathrm{y}, \mathrm{z})$, $\Delta \mathrm{T}_{k v}$ is base level (regional anomalies value) and $\mathrm{N}$ is a value that describes the anomaly attenuation rate commonly known as the structural index (degree of homogeneity).
In the interpretaion of magnetic data, Thompson $(1982)^{5}$ suggested that the index for a magnetic contact was less than 0.5. Reid et al. $(1990)^{6}$ said that: This value led to underestimates of depth, even when testing ideal models. They showed that the value for a sloping contact, in fact, zero, provided that an offset A was introduced. The appropriate form of Euler's equation is then:

$$
\begin{aligned}
& \left(\mathrm{x}-\mathrm{x}_{0}\right) \frac{\partial \Delta \mathrm{T}}{\partial \mathrm{x}}+\left(\mathrm{y}-\mathrm{y}_{0}\right) \frac{\partial \Delta \mathrm{T}}{\partial \mathrm{y}}+ \\
& \left(\mathrm{z}-\mathrm{z}_{0}\right) \frac{\partial \Delta \mathrm{T}}{\partial \mathrm{z}}=\mathrm{A}
\end{aligned}
$$

where, A incorporates amplitude, strike, and dip factors which couldn't be separated easily.

In this paper, we only estimated the depth to the top of the contacts by calculating the standard 3D-Euler deconvolution along the position of the structural faults identified from tilt angle.

\section{A combined Euler deconvolution and tilt angle method (Tilt_Euler)}

All calculations are made on the Oasis Montaj software version 8.4. The method consists of two parts:

\section{Calculating the 3D-Euler depth using the standard GX Euler3D:}

a. Create magnetic grid data for calculation (Euler3D $\rightarrow$ Grid data)

b.Calculate the vertical and horizontal derivatives of the grid data (Euler3D $\rightarrow$ Process Grid).

c. Calculate the Euler depth with input data including magnetic grid map and its horizontal maps $(\mathrm{dx}$, dy) and vertical maps (dz) (Euler3D $\rightarrow$ Standard Euler Deconvolution).

\section{Determinating the Euler3D depth along the positon of $O$ value of the tilt angle:}

a. Calculate the tilt angle using the standard MAGMAP. By default, the Oasis provides both the tilt angle and its horizontal gradient. (Magmap $\rightarrow$ Tilt Derivative)

b. Map the zero contour of the tilt angle without labels. (Map Tools $\rightarrow$ Contour)

c. Export the zero contour layer to a shapefile. (Map $\rightarrow$ Export)

d. Import the shapefile back into a Geosoft database. Specify "New database with shape database(s)". The zero contour will be represented in the shape database as $\mathrm{X}$ and $\mathrm{Y}$ channels. (Map $\rightarrow$ Import)

e. Determine the value of the standard Euler deconvolution at each $\mathrm{x}, \mathrm{y}$ coordinate, thereby creating another channel. (Grid Image $\rightarrow$ Utilities $\rightarrow$ Sample a Grid) 
f. Tidy up the database as desired, decimating points based on $\mathrm{X}$ and $\mathrm{Y}$ and windowing points based on depth.

g. Use colored symbols to plot the value of depth at each xy coordinate which is identified by zero values of the tilt angle. (Map tools $\rightarrow$ Symbols $\rightarrow$ Colored Range Symbols)

\section{Determination of fault dip angle and direc- tion}

In case of a geologic contact (fault surface/trace), the highest upward continuation corresponds to the magnetic response of the deepest part of the contact. If the contact is vertical, then the maxima of total horizontal gradient of upward continued fields are located at the same position. On the other hand, if the maxima systematically shift in horizontal direction, then the dip direction of the contact can be identified.

And the fault dip angle (from the horizontal) can be approximated by the method of Chiapkin ${ }^{21}$. Using the anomalous curves upward continuation at the different height levels, we calculated the corresponding total horizontal derivative of them and then determined the angle $\alpha$ by the formula:

$$
\cot \alpha=\frac{d}{h}
$$

where, $\mathrm{d}$ is the distance on the measuring line from the projection of the fault trace to the projection of the maximum point of the horizontal derivative of curve at the height $h$.

\section{RESULTS}

The data of South region (between latitudes $8.52^{\circ} \mathrm{N}$ and $11.76^{\circ} \mathrm{N}$, and longitudes $104.45^{\circ} \mathrm{E}$ and $107.50^{\circ} \mathrm{E}$ ) was the aeromagnetic map in 1985's of Department of Geology and Minerals of Vietnam, 1:200,000 in Southern Vietnam ${ }^{22}$. Data was recorded in digitized form (X, Y, Z text file) and was interpolated to grid data sized $178 \times 178$, spacing $2 \mathrm{~km}$. In which, the $X$ and $Y$ represent the longitude and latitude of this research area in meters respectively, while the $\mathrm{Z}$ represents the magnetic field intensity measured in nanoTesla.

\section{The magnetic anomalies map}

After removing the normal magnetic field was calculated by the formula of Nguyen Thi Kim Thoa $(1992)^{23}$, the magnetic anomalies map (Figure 2) showed that the magnetic anomalies were relatively stable, on which the anomalous bands prolonged to the North-South direction with positive - negative zones alternating.
In this paper, we used the RTP operator in Fourier domainat low latitudes of Xiong Li, $(2008)^{24}$, with I $=5^{\circ}, \mathrm{D}=-0.2^{\circ}, \mathrm{I}_{c}=90^{\circ}$, for reducing the magnetic anomalies from asymmetrical shapes to symmetrical ones and located over the sources ${ }^{25}$. The anomalies of RTP map (Figure 3) were more simple, symmetric, clear and did not introduce the linear artifacts along direction of the declination. The anomalies could be divided as follows:

\section{Some strong anomalies of the Bien Hoa sub- zone, Soc Trang swell bead and coastal hol- low in the east:}

\section{a. Northwest - Southeast direction:}

- Tay Ninh anomalies: this anomalous zone was complex, high amplitude and the negative and positive parts are alternate, including:

+ Go Dau anomaly: having positive value

+ Tay Ninh anomaly: this anomaly was quite complex, it seemed to belong to the anomalies which had Northeast - Southwest direction. It could be said that this area was the intersection of two different structures.

- Xuyen Moc anomalies: having negative value prolong to the Northwest - Southeast direction.

- Co Chien - Cho Lach anomalies: including Co Chien anomaly (negative part was elip form) and Cho Lach anomaly (isometric form).

\section{b. Northeast - Southwest direction}

- Bien Hoa anomalies: prolonged from the Northern Ho Chi Minh City to the Northern Bien Hoa, including:

+ Two anomalies in the Northern Bien Hoa: the negative and positive parts were alternate with a large anomaly in the west, the negative parts were larger in size and amplitude than the positive one and there was one small anomaly closer to the longitude $107^{\circ} \mathrm{E}$

+ Northern Ho Chi Minh City anomaly: the negative part was larger than the positive.

- South of Ben Tre and Soai Rap mouth anomalies: were a large anomaly extending from Soai Rap mouth to Ho Chi Minh City, including two anomalies: a smal one in the Western HCM city and a large one (the negative parts were larger in size and amplitude than the positive ones). Ben Tre anomaly was a large negative anomaly prolonging from the sea to the land and having the direction parallel with Tien River.

- Vinh Long - Ben Luc anomalies: including Vinh Long anomaly and Ben Luc anomaly which the negative parts were larger than the positive ones.

- South of Tra Vinh - Soc Trang anomalies: including Southern Tra Vinh anomaly with the negative and positive part having form of prolong, Soc Trang anomaly 


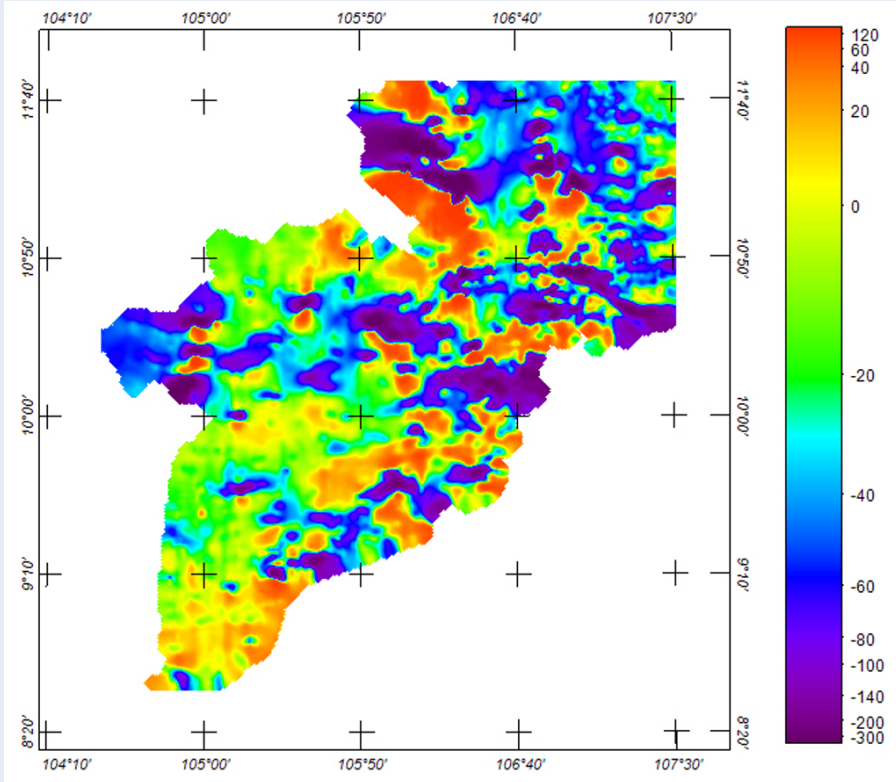

Figure 2: The magnetic anomalies map of the South region.

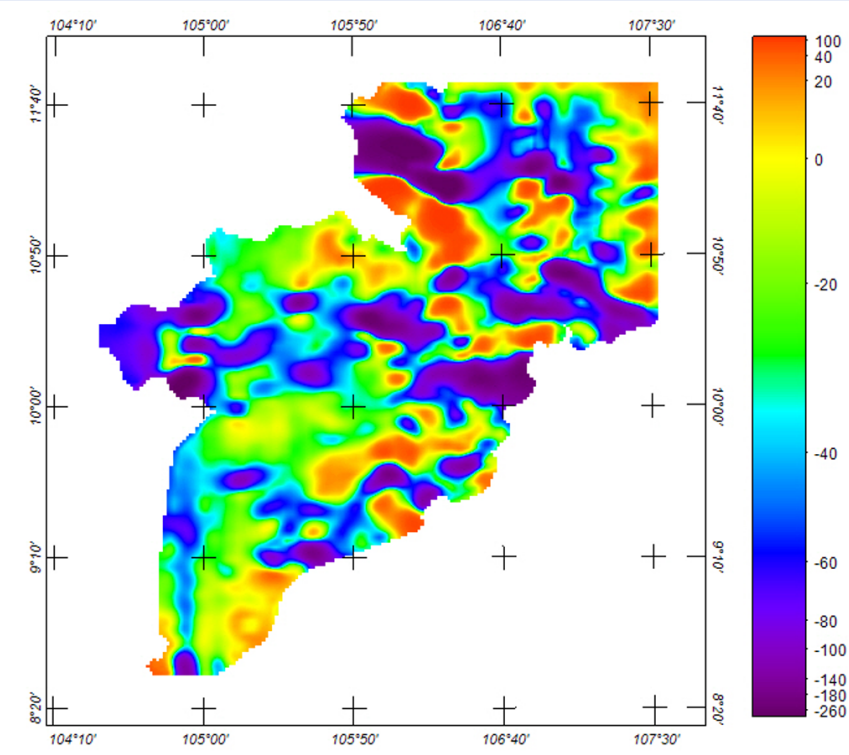

Figure 3: The RTP map of the South region. 
had a negative part with large size which was between the two positive ones.

- East of Dam Doi anomalies: the structure is prolonged to Southern Tra Vinh - Soc Trang anomalies; including two anomalies: Gia Rai and Dam Doi anomaly had alternating negative and positive parts.

\section{Some anomalies of the Dong Thap - Ca Mau} hollow

- Rach Gia - Long Xuyen anomalies: contour lines ran parallel, had two alternating negative and positive - Gia Rai - North of Ca Mau anomalies, including:

+ The Western Gia Rai anomaly: having negative value, the isometric form. It coincided with a negative gravity anomaly.

+ Northern Ca Mau anomaly: consists of two alternating negative and positive parts and large anomalies.

- Southern Ca Mau anomaly: ran parallel to the anomalous zone of Gia Rai - Northern Ca Mau.

- Dong Thap anomaly: consisted of a large anomaly alternating with two positive anomalies.

\section{Interpretation of the South region's mag- netic data by Tilt_Euler method}

As mentioned in the introduction, the 3D Euler Deconvolution method is used to estimate the depth of the field source with the RTP map, 20x20 window size, flight measured $300 \mathrm{~m}, 15 \%$ maximum depth error. The zero-structural index is used to estimated the position and depth of the source. The maximum depth to the top of the anomaly boundary is about $3100 \mathrm{~m}$. The depth result displays along the 0 value of the tilt angle (called the Tilt_Euler map) is shown in Figure 4. The result (Figure 4) shows that the zero contour of tilt angle tend to lie along boundaries of anomalies and along the faults of the longitudinal direction, Northwest - Southeast direction and Northeast - Southwest direction. These faults can be divided into 4 groups as follow:

- The faults of Longitudinal and Sub-longitudinal direction (LONG) (4 faults), including: Ca Mau - Chau $\operatorname{Doc}^{(F 14)}$, Ca Mau - Hong Ngu ${ }^{(F 15)}$, Binh Phuoc - Ba $\mathrm{Ria}^{(F 1)}$ and Tay Ninh - Tra Cu${ }^{(F 21)}$.

- The fault of Latitudinal and Sub-latitudinal direction (LAT)(1 faults): Cao Lanh - Soai $\operatorname{Rap}^{(F 11)}$.

- The faults of Northwest - Southeast direction (NW$S E)$ (5 faults), including: Sai Gon $\operatorname{River}^{(F 4)}$, Vam Co $\operatorname{Dong}^{(F 5)}$, Vam Co Tay ${ }^{(F 10)}$, Tien River ${ }^{(F 12)}$, Hau $\operatorname{River}^{(F 13)}$.

- The faults of Northeast - Southwest direction (NESW) (2 faults), including: Hon Dat - Tay $\operatorname{Ninh}^{(F 7)}$, $\mathrm{Ca} \mathrm{Mau}-\mathrm{Go}$ Cong Dong ${ }^{(F 23)}$.
Determination of the dip angle and dip direction of some faults

On the RTP map, at each fault, we ploted a line perpendicular to the fault and extracted the RTP anomaly values of each line. Then, using that values of each line to perform the upward continuation at the some different height: 3; 4; 5 and $10 \mathrm{~km}$; therefore, determinating the the dip angle and dip direction of faults by considering the location of maximum point of the horizontal derivative of measuring line at the different height levels.

Figure 6 is the graph of anomalies at the different height levels and the horizontal derivative of them at the measuring line perpendicular to the Hau river fault. Table 1 showed that maximum positions are determined at positions $33,37,39,46$; so, the fault trace shifted from Southwest to Northeast; dip angle was about $74^{\circ}$.

Figure 7 is the graph of anomalies at the different height levels and the horizontal derivative of them at the measuring line perpendicular to the $\mathrm{Ca} \mathrm{Mau}$ Chau Doc fault. Table 2 showed that maximum positions are determined at positions $66,63,60,43$; so, the fault trace shifted from East to West; dip angle was about $73^{\circ}$.

Similarly, to the remaining faults, the results of determining the dip angle and dip direction of the faults are shown in Table 3.

\section{DISCUSSION}

The magnetic anomalies map (Figure 2) showed that the magnetic anomalies were relatively stable, on which the anomalous bands prolonged to the NorthSouth direction with positive - negative zones alternating ${ }^{25}$. According to this map, the research area can be divided into two parts as a straight line from Moc Hoa to Doi Dam: the Eastern part (including Bien Hoa sub-zone, Soc Trang swell bead and coastal hollow in the east) had higher density of anomalies and the length of the anomalies were also greater; in while, the Western part (Dong Thap - Ca Mau hollow of the Can Tho zone) was a larger area, but with fewer anomalies, shorter anomalies length and some magnetic anomalies were isolated ${ }^{26}$. Most of the magnetic anomalies were usually distributed in a particular direction and these often coincided with the major faults in the region. This is even more evident in the RTP map (Figure 3). Almost strong anomalies are concentrated in the Eastern part. They consisted of the negative and postive ones alternating, the negative are usually larger in size and amplitude than the positive ones, forming the anomalous zones with the 


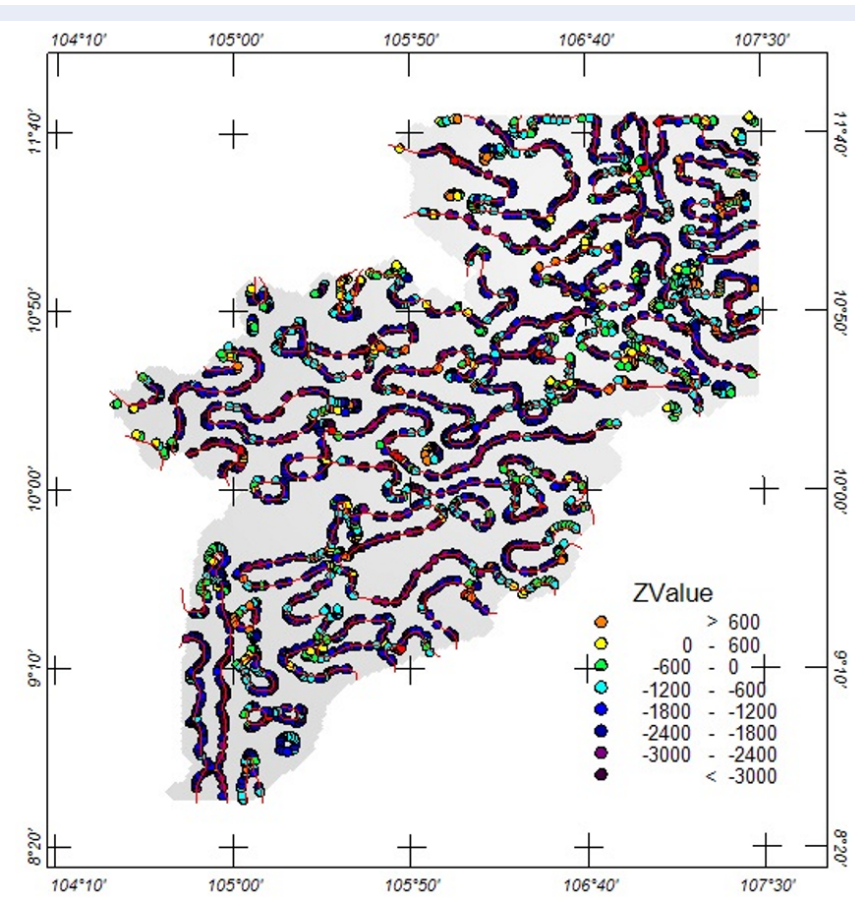

Figure 4: The Tilt_Euler map. Legend: theZero-contour of tilt map (red lines) overlain by Euler solutions(colored dots)

Table 1: The result of Hau river fault's dip angle

\begin{tabular}{llll}
\hline Height $(\mathrm{h})$ & Position $(\mathrm{n})$ & Alpha $\left(^{\circ}\right)$ & The average of alpha \\
\hline 3 & 33 & 0 & 73.6595 \\
4 & 37 & 68.1986 & \\
5 & 39 & 73.3008 & \\
10 & 46 & 79.4792 & \\
\hline
\end{tabular}

Table 2: The result of Ca Mau - Chau Doc fault's dip angle

\begin{tabular}{llll}
\hline Height $(\mathrm{h})$ & Position $(\mathrm{n})$ & Alpha $\left(^{\circ}\right)$ & The average of alpha \\
\hline 3 & 66 & 0 & 72.8042 \\
4 & 63 & 73.3008 & \\
5 & 60 & 73.3008 & \\
10 & 43 & 71.8110 & \\
\hline
\end{tabular}

major directions: NW-SE direction and NE-SW direction. While, the magnetic field of Dong Thap - Ca Mau was quite stable, only some anomalies ran along to the NE-SW direction.

By comparing the anomalies of the RTP map (Figure 3) with the Tilt_Euler map (Figure 4), it can be said that the strong anomalies are aligned with the major directions of the faults in the region because the faults are usually associated with magnetic rock. In Figure 5, there are 12 faults which are divided into 4 groups. And the faults of NW-SE direction and the faults of Longitudinal and Sub-longitudinal direction are faults which developed strongly in the early and late Cenozoic era respectively; and faults NE-SW direction are faults which developed strongly in Mesozoic era, these faults are difficult to detect in the RTP map. The result in Figure 6 and Figure 7 showed that: when elevating the field to different heights, the position of the maximum horizontal derivative depends on the dip direction of the contact (positive or negative angles). With the positive angle, the maxima systematically will shift in horizontal direction to the right (Figure 6b). In contrast, with the negative angle, the maxima systematically will shift in horizontal di- 


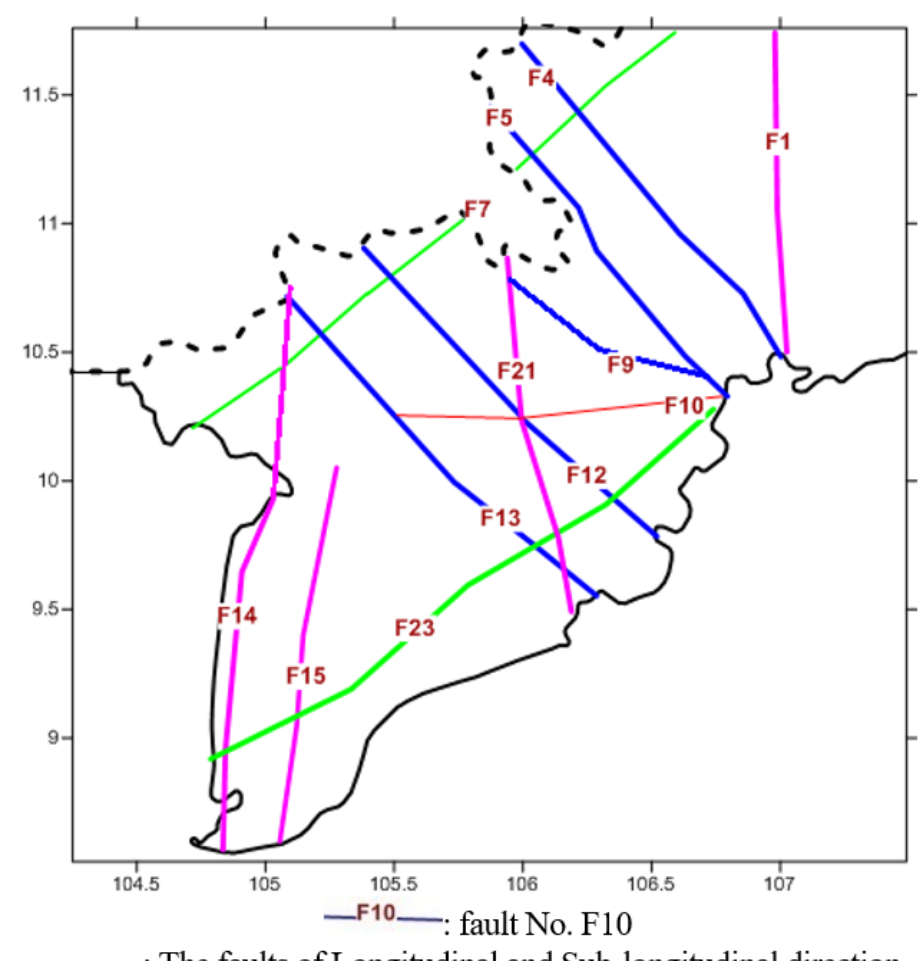

- : The faults of Longitudinal and Sub-longitudinal direction

- The fault of Latitudinal and Sub-latitudinal direction

- The faults of Northwest - Southeast direction

The faults of Northeast - Southwest direction

Figure 5: Delineation of some tectonic faults in research area.
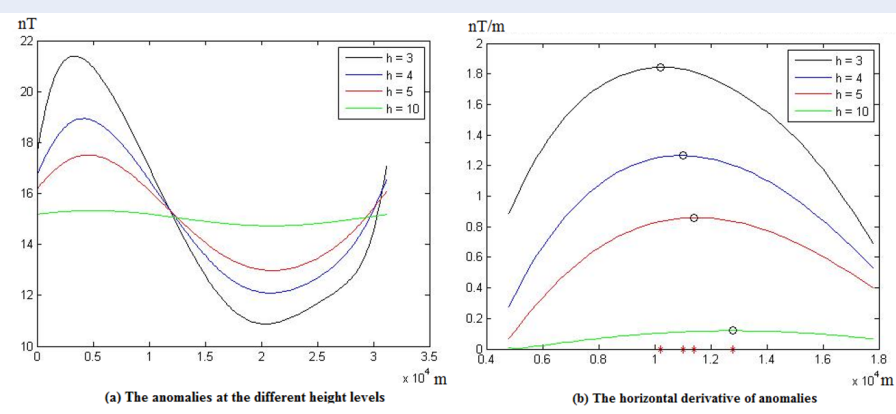

Figure 6: The measuring line perpendicular to the Hau river fault 

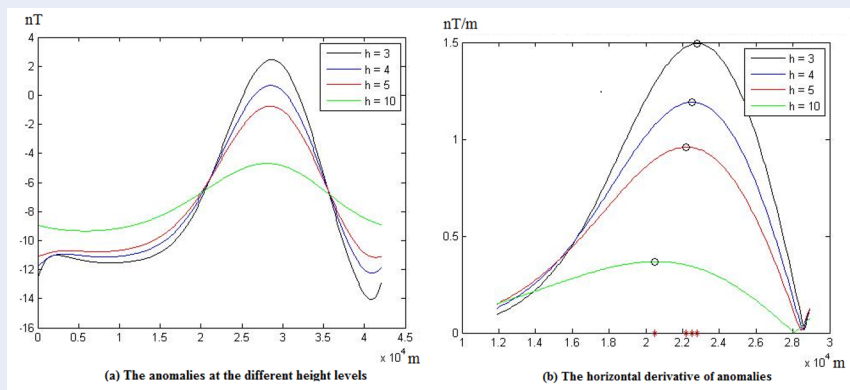

Figure 7: The measuring line perpendicular to the Ca Mau - Chau Doc fault.

Table 3: The characteristics of some faults in the South region

\begin{tabular}{llllll}
\hline No. & Symbol & Fault & Faulting direction & Dip direction & $\begin{array}{l}\text { Dip } \\
\text { angle }\end{array}$ \\
\hline 1 & F1 & Binh Phuoc - Ba Ria & Longitudinal and Sub-longitudinal & East & $72^{\circ}$ \\
2 & F4 & Sai Gon river & Northwest - Southeast & Southwest & $82^{\circ}$ \\
3 & F5 & Vam Co Dong & Northwest - Southeast & Southwest & $76^{\circ}$ \\
4 & F7 & Hon Dat - Tay Ninh & Northeast - Southwest & Southeast & $78^{\circ}$ \\
5 & F9 & Vam Co Tay & Northwest - Southeast & Northeast & $81^{\circ}$ \\
6 & F10 & Cao Lanh - Soai Rap & Latitudinal and Sub-latitudinal direction & Nam & $69^{\circ}$ \\
7 & F12 & Tien river & Northwest - Southeast & Northeast & $73^{\circ}$ \\
8 & F13 & Hau river & Northwest - Southeast & Northeast & $74^{\circ}$ \\
9 & F14 & Ca Mau - Chau Doc & Longitudinal and Sub-longitudinal & West & $73^{\circ}$ \\
10 & F15 & Ca Mau - Hong Ngu & Longitudinal and Sub-longitudinal & East & $65^{\circ}$ \\
11 & F21 & Tay Ninh - Tra Cu & Longitudinal and Sub-longitudinal & West & $65^{\circ}$ \\
12 & F23 & Ca Mau - Go Cong Dong & Northeast - Southwest & Southeast & $80^{\circ}$ \\
\hline
\end{tabular}

rection to the left (Figure 7b). Similarly to the remaining faults, the results of determining the dip angle and dip direction of the faults are shown.

The faults map showed that the faults metioned above matched with rivers and topographical boundaries in the research area ${ }^{11,27}$. There were many faults matching with the announced faults $9,12,22$. These results contributed with the previous studies $9,13,26,27$ to give and confirm the useful information on geological structure in the South region of Vietnam.

\section{CONCLUSION}

In this research, the magnetic anomalies map and the RTP were built for the initial evaluation of structure and characteristics of anomalies in the South region of Vietnam. In which, the RTP method at low lattitude is used to reduce some unwanted effects in the interpretation of the magnetic data such as: the peaks are shifted away from the magnetic contact and secondary peaks parallel to the contacts can appear.

Based on the Oasis Montaj software, we have developed a method of locating and estimating the depth of the faults by a combined 3D-Euler deconvolution and tilt angle. In addition, building a program to determine dip angle and dip direction of the faults by considering the location of maximum point of the total horizontal derivative of measuring line perpendicular to the faults at the different heights.

After that, applying to interpret the magnetic data of the South region, 12 faults and their the angle and the direction of the dip are determinated. This difference is due to the new approach in this article, the resulting faults are determinated on the Tilt_Euler map - the map is built based on the depth results along the the 0 value of the tilt angle. The maximum depth to the top of the faults is about $3100 \mathrm{~m}$. Research results are appropriate and the computing is automatic and quick. 
They are valuable tools for specifying the characteristics of the research area.

\section{ABBREVIATIONS}

3D: three dimensional

LAT: Latitudinal and Sub-latitudinal direction

LONG: Longitudinal and Sub-longitudinal direction

NE-SW: Northeast - Southwest direction

NW-SE: Northwest - Southeast direction

RTP: reduced to the magnetic pole

Tilt_Euler: A combined Euler deconvolution and tilt angle method

\section{COMPETING INTERESTS}

The authors declare no competing interests.

\section{AUTHORS' CONTRIBUTIONS}

HNH and LDV designed the study. HNH and LDV carried out study on Oasis Montaj software version 8.4, proposed a combined the Tilt angle and the Euler deconvolution methods and wrote code of RTP (by Matlab). HNH compute the positions and the depth to the top of the faults. LDV wrote code for determinating the fault dip angle and VVV analyzed data. LDV evaluated of the result. HNH and LDV wrote the paper. $\mathrm{HNH}$ edited all the figures. All authors read and approved the final manuscript.

\section{ACKNOWLEDGMENTS}

The present research was supported and adviced from Dr. Nguyen Ngoc Thu (South Vietnam Geological Mapping Division) and Assoc. Prof. Dr. Cao Dinh Trieu (Institute for Geophysics, VUSTA, Hanoi).

\section{REFERENCES}

1. Cordell L, Grauch VJS. Mapping basement magnetization zones from aeromagnetic data in the San Juan Basin. New Mexico, Presented at the 52nd Ann. Internat Mtg, Soc Explor Geophys, Dallas. 1985;

2. Spector A, Grant FS. Statistical models for interpreting aeromagnetic data. Geophysics. 1970;35:293-302.

3. Hartman RR, Teskey DJ, Friedberg J. A system for rapid digital aeromagnetic interpretation. Geophysics. 1971;36:891-918.

4. Jain S. An automatic method of direct interpretation of magnetic profiles. Geophysics. 1976;41:531-541.

5. Thompson DT. EULDPH A new technique for making computer-assisted depth estimates from magnetic data. Geophysics. 1982;47:31-37.
6. Reid AB, Allsop JM, Granser H, Millet AJ, Somerton IW. Magnetic interpretation in three dimensions using Euler deconvolution. Geophysics. 1990;55:80-91.

7. Salem A, Williams SE, Fairhead JD, Ravat D, Smith R. Tilt-depth method: A simple depth estimation method using firstorder magnetic derivatives. The Leading Edge. 2007;26:1502-1505.

8. Salem A, Williams SE, Samson E, Fairhead JD, Ravat D, Blakely RJ. Sedimentary basins reconnaissance using the magnetic tilt-depth method. Exploration Geophysics. 2010;41:198-209.

9. Trieu CD. Pham Huy Long, Tectonic fault in Vietnam. Science and Technics Publishing House; 2002. .

10. Minh LH, Hung LV, Trieu CD. Using the maximum horizontal gradient vector to interpret magnetic and gravity data in Vietnam. Journal of Sciences of the Earth. 2002;24(1):67-80.

11. Trieu CD. Geophysical field and crustal structure of Vietnam territory. Science and Technics Publishing House; 2005 . .

12. Hai DT, Trieu CD. Main active faults and earthquake in South Vietnam territory. Journal of Geology A. 2006;297:11-23.

13. Hai NH, An NTT, Liet DV, Thu NN. Determination of faults in the Southern Vietnam using gravity data. Proceedings Workshop on capacity building on geophysical technology in mineral exploration and assessment on land, sea and island. Publishing house for Science and Technology; 2016. 95-102.

14. Miller HG, Singh V. Potential field tilt A new concept for location of potential field sources. Journal of App Geophysics. 1994;32:213-217.

15. Verduzco B. New insights into magnetic derivative for structural mapping. The Leading Edge. 2004;23:116-119.

16. Hinze WJ, von Frese RRB, Saad AH. Oasis montaj Tutorial for Gravity and Magnetic Exploration Principles, Practices, and Applications. Cambridge University Press; 2013. .

17. Roest WR, Verhoef J, Pilkington M. Magnetic inter-pretation using the 3-D analytic signal. Geophysics. 1992;57:116-125.

18. Ravat $D$. Analysis of the Euler method and its applicability in environmental investigations. Journal of Environmental \& Engineering Geophysics. 1996;1:229-238.

19. Durrheim RJ, Cooper GRJ. EULDEP: A program for the Euler deconvolution of magnetic and gravity data. Computer \& Geosciences. 1998;24:545-550.

20. Barbosa V, Sliva J, Medeiros W. Stability analysis and improvement of structural index in Euler deconvolution. Geophysics. 1990;64:48-60.

21. Chiapkin KF. The analysis of gravity data in the study of deep crust structure.Vnigeophizika. Moskva, 300 pp. (Russian); 1969.

22. Son NX. Interpretation of geological structure of South Vietnam by aeromagnetic data at 1:200,000 scale, Candidate of Science thesis. Hanoi University of Mining and Geology; 1996.

23. Thoa NTK. Geomagnetic field and surveying results in Vietnam. Science and Technics Publishing House; 2010.

24. Li X. Magnetic reduction-to-the-pole at low latitudes: Observations and considerations. The Leading Edge. 2008;27(8):990-1002.

25. Tuan TV, Liet DV. Geomagnetic field and magnetic exploration. VNU-HCM Publishing House; 2013. .

26. Liet DV. Analysis of magnetic and gravity data in South of Vietnam, Candidate of Science thesis. Ho Chi Minh City Combined University; 1995.

27. Trieu CD, Long PH, Hai DT, Dung PT, Dung LV, Bach MX, et al. The lithosphere and mantle in South-East Asian. Science and Technics Publishing House; 2017. . 